\title{
Lack of calcium oscillation causes failure of oocyte activation after intracytoplasmic sperm injection in pigs
}

\author{
Michiko NAKAI ${ }^{1}$, Junya ITO' ${ }^{2}$, Shun-ichi SUZUKI ${ }^{1}$, Dai-ichiro FUCHIMOTO'), \\ Shoichiro SEMBON ${ }^{1}$, Misae SUZUKI ${ }^{1}$, Junko NOGUCHI ${ }^{1}$, Hiroyuki KANEKO'), \\ Akira ONISHI ${ }^{3)}$, Naomi KASHIWAZAKI ${ }^{2)}$ and Kazuhiro KIKUCHI ${ }^{1,4)}$ \\ 1) Division of Animal Sciences, Institute of Agrobiological Sciences, National Agriculture and Food Research Organization, \\ Ibaraki 305-8602, Japan \\ 2) Laboratory of Animal Reproduction, School of Veterinary Medicine, Azabu University, Kanagawa 252-5201, Japan \\ 3) College of Bioresource Sciences, Nihon University, Kanagawa 252-0880, Japan \\ 4) The United Graduate School of Veterinary Science, Yamaguchi University, Yamaguchi 753-8515, Japan
}

\begin{abstract}
In pigs, the efficiency of embryo production after intracytoplasmic sperm injection (ICSI) is still low because of frequent failure of normal fertilization, which involves formation of two polar bodies and two pronuclei. To clarify the reasons for this, we hypothesized that ICSI does not properly trigger sperm-induced fertilization events, especially intracellular $\mathrm{Ca}^{2+}$ signaling, also known as $\mathrm{Ca}^{2+}$ oscillation. We also suspected that the use of in vitro-matured oocytes might negatively affect fertilization events and embryonic development of sperm-injected oocytes. Therefore, we compared the patterns of $\mathrm{Ca}^{2+}$ oscillation, the efficiency of oocyte activation and normal fertilization, and embryo development to the blastocyst stage among in vivo- or in vitro-matured oocytes after ICSI or in vitro fertilization (IVF). Unexpectedly, we found that the pattern of Ca ${ }^{2+}$ oscillation, such as the frequency and amplitude of $\mathrm{Ca}^{2+}$ rises, in oocytes after ICSI was similar to that in oocytes after IVF, irrespective of the oocyte source. However, half of the oocytes failed to become activated after ICSI and showed no $\mathrm{Ca}^{2+}$ oscillation. Moreover, the embryonic development of normal fertilized oocytes was reduced when in vitro-matured oocytes were used, irrespective of the fertilization method employed. These findings suggest that low embryo production efficiency after ICSI is attributable mainly to poor developmental ability of in vitro-matured oocytes and a lack of $\mathrm{Ca}^{2+}$ oscillation, rather than the pattern of oscillation.
\end{abstract}

Key words: $\mathrm{Ca}^{2+}$ oscillation, Fertilization, Intracytoplasmic sperm injection, Phospholipase C- $\zeta$, Pig

(J. Reprod. Dev. 62: 615-621, 2016)

O vulated mammalian oocytes remain arrested at metaphase of the second meiosis (M-II) until fertilization. Fertilizing sperm evoke repetitive rises in the intracellular level of free $\mathrm{Ca}^{2+}$, known as $\mathrm{Ca}^{2+}$ oscillation, immediately after sperm-oocyte fusion [1]. Previous studies have indicated that sperm-specific phospholipase $\mathrm{C}-\zeta$ (PLC $\zeta)$ is delivered from the fertilizing sperm into the ooplasm triggering $\mathrm{Ca}^{2+}$ oscillation in mouse $[2,3]$, rat [3], human $[3,4]$, cynomolgus monkey [4], bovine [5, 6], pig [7, 8], equine $[9,10]$, medaka (fish) [11], chicken [12], and quail [13]. PLC $\zeta$ hydrolyzes phosphatidylinositol 4,5-bisphosphate $\left(\mathrm{PIP}_{2}\right)$ into 1,4,5-trisphosphate $\left(\mathrm{IP}_{3}\right)$ and diacylglycerol. Binding of $\mathrm{IP}_{3}$ to its receptors $\left(\mathrm{IP}_{3} \mathrm{Rs}\right)$ on the endoplasmic reticulum (ER) membrane elicits the release of $\mathrm{Ca}^{2+}$ from ER, resulting in $\mathrm{Ca}^{2+}$ oscillation [14].

Intracytoplasmic sperm injection (ICSI) is a useful tool for producing live offspring from immotile sperm, and for preventing

Received: July 29, 2016

Accepted: September 8, 2016

Published online in J-STAGE: September 30, 2016

(C)2016 by the Society for Reproduction and Development

Correspondence: M Nakai (e-mail: nakai3@affrc.go.jp)

This is an open-access article distributed under the terms of the Creative Commons Attribution Non-Commercial No Derivatives (by-nc-nd) License $<$ http://creativecommons.org/licenses/by-nc-nd/4.0/>. polyspermy, which frequently occurs with in vitro fertilization (IVF) in pigs. However, the efficiency of in vitro embryo production by ICSI and the quality of the embryos are inferior compared to IVF. It has also been reported that the pattern of $\mathrm{Ca}^{2+}$ oscillation in human oocytes after ICSI differs from that in oocytes penetrated with sperm [15]. The pattern of $\mathrm{Ca}^{2+}$ oscillation is suggested to play an important role in the resumption of meiosis, recruitment of maternal mRNAs, formation of pronucleus (PN), expression of genes, and development to term [16-18].

Despite the use of in vitro-matured pig oocytes in a wide range of studies, their developmental capacity is lower than that of in vivo-matured oocytes [19]. Furthermore, in vitro-matured oocytes from humans are deficient in $\mathrm{Ca}^{2+}$ release in response to $\mathrm{IP}_{3}$ due to their inability to synthesize the $\mathrm{IP}_{3}$ receptor protein [20] compared to in vivo-matured oocytes.

Therefore, we have hypothesized that the patterns of $\mathrm{Ca}^{2+}$ oscillation in in vitro-matured oocytes and sperm-injected oocytes are different from that in in vivo-matured oocytes after IVF. Such different patterns bring about failure of oocyte activation and normal fertilization, which involves the formation of two polar bodies and two PNs, and a reduction of embryonic developmental ability. To our knowledge, no previously reported study has compared the pattern of $\mathrm{Ca}^{2+}$ oscillation in sperm-penetrated oocytes with that in oocytes after 
ICSI in pigs. Herein, we investigated the pattern of $\mathrm{Ca}^{2+}$ oscillation, such as the number, amplitude, and interval of $\mathrm{Ca}^{2+}$ rises, and in vitro developmental capacity after ICSI or IVF using in vivo- or in vitro-matured pig oocytes.

\section{Materials and Methods}

Protocols for the use of animals were approved by the Animal Care Committee of the Institute of Agrobiological Sciences, National Agriculture and Food Research Organization, Japan. All reagents were purchased from Sigma Chemical Company (St. Louis, MO, USA) unless otherwise stated.

\section{Preparation of in vivo-matured oocytes}

Prepubertal ( $<6$ months of age) crossbred gilts (Landrace, Large White, and Duroc breeds) received 1500 IU of equine chorionic gonadotropin (eCG: PMS A for Animal; ZENOAQ, Fukushima, Japan) and, $72 \mathrm{~h}$ later, $750 \mathrm{IU}$ of human chorionic gonadotropin (hCG: Puberogen; ZENOAQ). At $44 \mathrm{~h}$ after administration of hCG, the gilts were euthanatized and their ovaries, oviducts, and uteri were collected. Cumulus-oocyte complexes (COCs) were collected by oviduct perfusion and washed with phosphate-buffered saline (PBS; Nissui Pharmaceutical, Tokyo, Japan) supplemented with $5 \mathrm{mg} / \mathrm{ml}$ bovine serum albumin (BSA; Fraction V) and $150 \mathrm{IU} / \mathrm{ml}$ hyaluronidase. Denuded oocytes with the first polar body were harvested under a stereomicroscope and used as in vivo-matured oocytes.

\section{Preparation of in vitro-matured oocytes}

Ovaries from prepubertal crossbred gilts (Landrace, Large White, and Duroc breeds) were obtained at a local slaughterhouse and transported to the laboratory at $35^{\circ} \mathrm{C}$. COCs were collected from follicles 2-6 $\mathrm{mm}$ in diameter in glucose-free, HEPES-buffered Tyrode medium [21]. Maturation culture was performed as reported previously [22]. In brief, COCs were cultured in six-well dishes (Research Institute for Functional Peptides, Yamagata, Japan) for 20-22 h in $100 \mu \mathrm{l}$ of maturation medium, a modified North Carolina State University (NCSU)-37 solution [23] containing 10\% (v/v) porcine follicular fluid, $0.6 \mathrm{mM}$ cysteine, $50 \mu \mathrm{M} \beta$-mercaptoethanol, $1 \mathrm{mM}$ dibutyl cAMP (dbcAMP), $10 \mathrm{IU} / \mathrm{ml} \mathrm{eCG}$, and $10 \mathrm{IU} / \mathrm{ml} \mathrm{hCG}$. They were subsequently cultured for $24 \mathrm{~h}$ in maturation medium without dbcAMP and hormones. Maturation culture was carried out at $39^{\circ} \mathrm{C}$ in an atmosphere of $\mathrm{CO}_{2}, \mathrm{O}_{2}$, and $\mathrm{N}_{2}$ adjusted to $5 \%$, $5 \%$, and $90 \%$, respectively $\left(5 \% \mathrm{CO}_{2}\right.$ and $\left.5 \% \mathrm{O}_{2}\right)$. After maturation culture, cumulus cells were removed from the oocytes by treatment with $150 \mathrm{IU} / \mathrm{ml}$ hyaluronidase and gentle pipetting. Denuded oocytes with a first polar body were harvested under a stereomicroscope and used as in vitro-matured oocytes.

\section{Preparation of sperm}

Epididymal spermatozoa were collected from a Landrace boar and cryopreserved [24, 25]. The spermatozoa were thawed in Medium 199 (with Earle's salts; Thermo Fisher Scientific, Waltham, MA, USA) adjusted to $\mathrm{pH} 7.8$ and centrifuged at $600 \times g$ for $2 \mathrm{~min}$. For IVF, the sperm pellet was resuspended in Medium $199(\mathrm{pH}$ 7.8), preincubated at $38^{\circ} \mathrm{C}$ for $15 \mathrm{~min}$ in Medium 199 (pH 7.8), and used for IVF. For ICSI, the sperm pellet was resuspended in PBS supplemented with $5 \mathrm{mg} / \mathrm{ml}$ BSA (PBS-BSA) and maintained at room temperature $\left(25^{\circ} \mathrm{C}\right)$ until ICSI.

\section{Sperm injection procedure}

Two solutions were prepared for ICSI: (1) for oocytes: a modified NCSU-37 solution without glucose but supplemented with $0.17 \mathrm{mM}$ sodium pyruvate, $2.73 \mathrm{mM}$ sodium lactate (Kanto Chemical, Tokyo, Japan), 4 mg/ml BSA, $50 \mu \mathrm{M} \beta$-mercaptoethanol (IVC-PyrLac [22]) and $20 \mathrm{mM}$ HEPES (Dojindo, Kumamoto, Japan), with the osmolality adjusted to $285 \mathrm{mOsm} / \mathrm{kg}$ (IVC-PyrLac-HEPES [26]); (2) for sperm: IVC-PyrLac-HEPES supplemented with 4\% (w/v) polyvinyl pyrrolidone (PVP360) (IVC-PyrLac-HEPES-PVP). Spermatozoa were injected as described previously [26]. About 20 oocytes were transferred to a 20- $\mu$ l drop of IVC-PyrLac-HEPES. The solution containing the mature oocytes was placed on the cover of a plastic dish (Falcon 35-1005; Becton Dickinson and Company, Franklin Lakes, NJ, USA). A small volume $(0.5 \mu \mathrm{l})$ of the sperm suspension was then transferred to a $2-\mu 1$ drop of IVC-PyrLac-HEPES-PVP, which had been placed close to the drops used for the oocytes. All drops were covered with paraffin oil (Paraffin Liquid; Nacalai Tesque, Kyoto, Japan). The spermatozoa were immobilized and injected into the ooplasm using a piezo-actuated micromanipulator (PMAS-CT150; Prime Tech, Tsuchiura, Japan). Sperm-injected oocytes were then cultured in IVC-PyrLac at $38.5^{\circ} \mathrm{C}, 5 \% \mathrm{CO}_{2}$, and $5 \% \mathrm{O}_{2}$.

\section{In vitro fertilization (IVF) procedure}

IVF was carried out according to the method described by Kikuchi et al. [22]. The oocytes were washed three times in pig fertilization medium (Pig-FM [27]) and then placed in individual $80-\mu$ drops of the same medium that had been covered with warm paraffin oil. Next, $10 \mu$ of preincubation medium containing sperm was added to each fertilization drop to give a final concentration of $1 \times 10^{5} \mathrm{sperm} /$ $\mathrm{ml}$ and then co-incubated for $3 \mathrm{~h}$ at $39^{\circ} \mathrm{C}$ under $5 \% \mathrm{CO}_{2}$ and $5 \% \mathrm{O}_{2}$.

\section{In vitro culture (IVC)}

At $10 \mathrm{~h}$ after ICSI or insemination, oocytes were placed in 700 $\mu 1$ of IVC-PyrLac-HEPES and centrifuged at $10,000 \times g$ at $37^{\circ} \mathrm{C}$ for $20 \mathrm{~min}$ in a microcentrifuge [28]. The centrifuged oocytes were examined for their content of PN and polar bodies under an inverted microscope. Normal fertilized oocytes that had two polar bodies and two PNs were cultured for 6 days.

Two types of IVC medium were prepared [22]. The first was IVC-PyrLac. The second contained $5.55 \mathrm{mM}$ glucose (Wako Pure Chemical Industries, Osaka, Japan), as originally reported in the NCSU-37 medium, and supplemented with $4 \mathrm{mg} / \mathrm{ml} \mathrm{BSA}$ and 50 $\mathrm{mM} \beta$-mercaptoethanol (IVC-Glu). For the first 2 days, IVC-PyrLac was used. The medium was changed once, to IVC-Glu, on the second day and this medium was used for subsequent culture for 4 days. The IVC was carried out at $38.5^{\circ} \mathrm{C}, 5 \% \mathrm{CO}_{2}$, and $5 \% \mathrm{O}_{2}$.

\section{Assessment of oocyte activation, normal fertilization, and embryonic development}

The oocytes and cultured embryos were mounted on glass slides and fixed in $25 \%(\mathrm{v} / \mathrm{v})$ acetic acid in ethanol, stained with $1 \%(\mathrm{w} / \mathrm{v})$ orcein in $45 \%(\mathrm{v} / \mathrm{v})$ acetic acid, and observed under a phase-contrast microscope. The nuclear status of the oocytes was observed at $10 \mathrm{~h}$ 
after injection or insemination and was categorized into three states: (1) metaphase-II: M-II; (2) transitional period, in which oocytes had resumed meiosis but before any PN formation, i.e., all in anaphase-II, telophase-II, or metaphase-III; and (3) formation of more than 1 PN $(1 \mathrm{PN} \leq)$ [29]. We defined normal fertilization as a zygote with two polar bodies and two PNs. The rate of blastocyst formation and the mean number of cells per blastocyst were also examined on Day 6 (the day of injection or insemination was defined as Day 0).

\section{Measurement of intracellular calcium}

After sperm injection or insemination, each oocyte was loaded with $50 \mu$ g Fura-PE3 (Santa Cruz Biotechnology, Dallas, Texas, USA) supplemented with $0.02 \%$ Pluronic F-127 (Thermo Fisher Scientific) at $38^{\circ} \mathrm{C}$ for $30 \mathrm{~min}$. The Fura-PE3 prelabeled oocytes were monitored in 50- $\mu$ l drops of PyrLac-HEPES without BSA on a thin glass coverslip (Electron Microscopy Sciences, Hatfield, PA, USA) fitted into a stainless steel well, covered with paraffin oil. The $\mathrm{Ca}^{2+}$ imaging was performed using an inverted microscope and AQUACOSMOS (Hamamatsu Photonics, Hamamatsu, Japan). Measurements were taken every minute and are reported as the ratios of 340/380 nm fluorescence. The amplitude of $\mathrm{Ca}^{2+}$ rise was calculated by subtracting the fluorescence ratio before $\mathrm{Ca}^{2+}$ rise from that in the peak of $\mathrm{Ca}^{2+}$ rise. After measurement, $\mathrm{PN}$ formation in each oocyte was observed individually by aceto-orcein staining, and the $\mathrm{Ca}^{2+}$ response in normal fertilized oocytes was determined.

\section{Statistical analysis}

All percentage data were subjected to arcsine transformation [30] before statistical analysis. The data for activated oocytes, blastocyst formation, and number of cells per blastocyst were analyzed by two-way analysis of variance (ANOVA) using the Statcel 2 program (OMS Publishing, Saitama, Japan). Furthermore, the data for calcium measurement were analyzed by ANOVA and Tukey's multiple range test. Differences were considered significant at $\mathrm{P}<0.05$. All data were expressed as mean \pm SEM. Experiments were repeated more than three times.

\section{Results}

\section{Failure of oocyte activation after ICSI}

The nuclear status of in vivo- and in vitro-matured oocytes after IVF and ICSI (vivo-ICSI, vitro-ICSI, vivo-IVF, and vitro-IVF, respectively) was investigated (Fig. 1, Table 1). Regardless of their source, more than half of the oocytes after ICSI remained at the M-II stage (vivo-ICSI and vitro-ICSI, $51.7 \pm 3.8 \%$ and 56.4 $\pm 5.2 \%$, respectively). In contrast, all oocytes in the IVF groups resumed the second meiosis. Statistical analysis revealed that the method of fertilization significantly affected the resumption of second meiosis $(\mathrm{P}<0.001)$. The proportions of oocytes showing formation of more than $1 \mathrm{PN}$ after IVF (vivo-IVF and vitro-IVF, $100 \%$ and $88.2 \pm 6.4 \%$, respectively) were higher than those after ICSI (vivo-ICSI and vitro-ICSI, $44.8 \pm 6.5 \%$ and $28.2 \pm 5.1 \%$, respectively). The differences in the two effects, oocyte source and method of fertilization, were also statistically significant $(\mathrm{P}<0.01)$; the F-value for the fertilization method was particularly high, meaning that it had a more important effect on PN formation. In addition, in

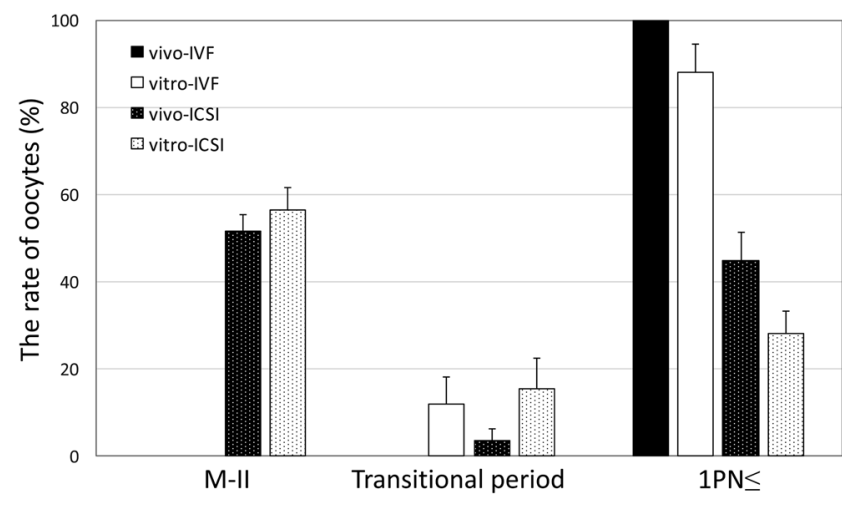

Fig. 1. The induction of oocyte activation in in vivo- or in vitro-matured oocytes after IVF or ICSI. At $10 \mathrm{~h}$, oocytes were classified into the following three categories: (1) M-II, metaphase-II; (2) transitional period: total of anaphase-II, telophase-II, and metaphase-III stages; and (3) $1 \mathrm{PN} \leq$ : formation of more than one pronucleus. Data are presented as mean \pm SEM for more than three separate experiments.

Table 1. Two-way ANOVA of the status of in vivo- or in vitro- matured oocyte nuclei after IVF or ICSI

\begin{tabular}{|c|c|c|c|c|}
\hline \multirow[b]{2}{*}{ Source } & \multirow[b]{2}{*}{$\mathrm{DF}^{\mathrm{a}}$} & \multicolumn{3}{|c|}{ F-value } \\
\hline & & M-II d & $\begin{array}{c}\text { Transitional } \\
\text { period }^{\mathrm{e}}\end{array}$ & $\mathrm{PN}^{\mathrm{f}}$ \\
\hline Source of oocytes ${ }^{b}$ & 1 & 4.12337 & 3.85167 & $16.4186 * *$ \\
\hline Fertilization methods ${ }^{\mathrm{c}}$ & 1 & $113.701 * * *$ & 0.63273 & $110.623 * * *$ \\
\hline
\end{tabular}

${ }^{a}$ degree of freedom. ${ }^{b}$ in vivo- or in vitro-matured oocytes. ${ }^{c}$ IVF or ICSI. ${ }^{\mathrm{d}}$ M-II: metaphase-II. ${ }^{\mathrm{e}}$ transitional period: total of anaphase-II, telophase-II, and metaphase-III stages. ${ }^{\mathrm{f}} \mathrm{PN}$ : formation of more than one pronucleus. ** $\mathrm{P}<0.01$, *** $\mathrm{P}<0.001$.

vivo-matured oocytes supported $\mathrm{PN}$ formation to a greater extent than in vitro-matured oocytes. There were no significant inter-group differences in the proportions of oocytes in the transitional period.

\section{Similarity of $\mathrm{Ca}^{2+}$ oscillation patterns in oocytes after ICSI and IVF}

The frequency, amplitude and interval of $\mathrm{Ca}^{2+}$ oscillations in normal fertilized oocytes after IVF or ICSI were investigated (Table 2). The typical patterns of $\mathrm{Ca}^{2+}$ oscillation in each treated oocyte are shown in Fig. 2. We consider that the pattern of $\mathrm{Ca}^{2+}$ oscillation in in vivo-matured oocytes, penetrated and activated by sperm, is closest to that in the in vivo "physiologically fertilized" oocytes. Therefore, the pattern of $\mathrm{Ca}^{2+}$ oscillation such as number, interval, and amplitude of $\mathrm{Ca}^{2+}$ rises in the vivo-IVF group was set as the basis for comparison among the patterns of $\mathrm{Ca}^{2+}$ oscillation in each group. The pattern from the vivo-IVF group was characterized as a low frequency of oscillation (1-2 times/4 h), a long interval between each $\mathrm{Ca}^{2+}$ rise $(156 \pm 19.7 \mathrm{~min})$, and a rise in $\mathrm{Ca}^{2+}$ level of $0.97 \pm$ 0.07. It seems that this $\mathrm{Ca}^{2+}$ oscillation pattern is typical in pigs. The vitro-IVF and vivo-ICSI groups also showed similar frequencies, amplitudes, and intervals of $\mathrm{Ca}^{2+}$ oscillation compared with the 
Table 2. $\mathrm{Ca}^{2+}$ responses in normal fertilized* pig oocytes after IVF or ICSI

\begin{tabular}{|c|c|c|c|c|c|c|c|c|}
\hline $\begin{array}{c}\text { Source of } \\
\text { oocytes }\end{array}$ & $\begin{array}{c}\text { Fertilization } \\
\text { methods }\end{array}$ & $\begin{array}{c}\text { Total no. of } \\
\text { oocytes }\end{array}$ & $\begin{array}{c}\text { No. of } \\
\text { 2PB2PN }\end{array}$ & $\begin{array}{c}\text { No. of oocytes } \\
\text { with } \mathrm{Ca}^{2+} \text { signal }\end{array}$ & $\begin{array}{c}\mathrm{Ca}^{2+} \text { rise } \\
\text { number }\end{array}$ & $\begin{array}{c}\text { No. of oocytes } \\
(\%) * *\end{array}$ & $\begin{array}{l}\text { Amplitude of } \\
\mathrm{Ca}^{2+} \text { rise ** }\end{array}$ & $\begin{array}{c}\mathrm{Ca}^{2+} \text { rise interval } \\
\quad(\mathrm{min}) * *\end{array}$ \\
\hline \multirow[t]{3}{*}{ in vivo } & ICSI & 41 & 17 & 9 & 1 & $5(55.6 \pm 17.4)$ & & \\
\hline & & & & & 2 & $3(33.3 \pm 18.1)$ & $0.78 \pm 0.07$ & $120 \pm 23.7^{\mathrm{a}}$ \\
\hline & & & & & $3<$ & $1(11.1 \pm 8.3)$ & & \\
\hline \multirow[t]{3}{*}{ in vitro } & ICSI & 97 & 32 & 18 & 1 & $11(61.1 \pm 13.7)$ & & \\
\hline & & & & & 2 & $4(22.2 \pm 11.3)$ & $0.92 \pm 0.06$ & $37.1 \pm 6.6^{b}$ \\
\hline & & & & & $3<$ & $3(16.7 \pm 7.9)$ & & \\
\hline \multirow[t]{3}{*}{ in vivo } & IVF & 56 & 17 & 7 & 1 & $4(57.1 \pm 22.4)$ & & \\
\hline & & & & & 2 & $3(42.9 \pm 22.4)$ & $0.97 \pm 0.07$ & $156 \pm 19.7^{\mathrm{a}}$ \\
\hline & & & & & $3<$ & $0(0)$ & & \\
\hline \multirow[t]{3}{*}{ in vitro } & IVF & 117 & 30 & 15 & 1 & $11(73.3 \pm 12.4)$ & & \\
\hline & & & & & 2 & $3(20.0 \pm 7)$ & $0.9 \pm 0.06$ & $106.5 \pm 21.4^{\mathrm{a}}$ \\
\hline & & & & & $3<$ & $1(6.7 \pm 6.3)$ & & \\
\hline
\end{tabular}

* Oocytes formed two polar bodies and two pronuclei. ${ }^{* *}$ Mean \pm SEM for oocytes that exhibited $\mathrm{Ca}^{2+}$ oscillations. ${ }^{\mathrm{a}-\mathrm{b}}$ Values with different superscripts within same column are significantly different $(\mathrm{P}<0.01)$.

vivo-IVF group because there was no significant difference among those categories. The vitro-ICSI also showed a low frequency of oscillation (1-4 times/4 h) and a rise in $\mathrm{Ca}^{2+}$ level of $0.92 \pm 0.06$; however, the interval between each $\mathrm{Ca}^{2+}$ rise in in vitro-matured oocytes after ICSI was shorter $(37.1 \pm 6.6 \mathrm{~min})$ than that in the other groups. Nevertheless, more than half of the oocytes with $\mathrm{Ca}^{2+}$ oscillation in the vitro-ICSI group showed a single $\mathrm{Ca}^{2+}$ rise like the other groups. These data indicated that the sperm-injected oocytes and in vitro-matured oocytes are able to develop a $\mathrm{Ca}^{2+}$ oscillation pattern which is similar to that of in vivo-matured oocytes after IVF. Yet, most of the oocytes that failed to undergo PN formation after ICSI showed no $\mathrm{Ca}^{2+}$ signal. Lastly, in a few oocytes that remained at the M-II stage, a low amplitude $\mathrm{Ca}^{2+}$ oscillation was observed (Fig. 3, Table 3).

\section{Developmental ability of normal fertilized oocytes after ICSI and IVF}

We compared the ability of embryos to develop into blastocysts, and the mean number of cells per blastocyst, after ICSI or IVF (Fig. 4, Table 4). The proportions of embryos undergoing blastocyst formation in the vivo-IVF, vivo-ICSI, vitro-IVF, and vitro-ICSI groups were $80.8 \pm 7.1 \%, 85.7 \pm 6.3 \%, 71.9 \pm 6.2 \%$, and $65.0 \pm 10.9 \%$, respectively. Statistical analysis revealed that blastocyst formation was affected by the oocyte source, and not by the fertilization method. The mean numbers of cells per blastocyst in the vivo-IVF, vivo-ICSI, vitro-IVF, and vitro-ICSI groups were $91.8 \pm 7.0,65.6 \pm 6.7,67.1$ \pm 5.6 , and $54.3 \pm 7.0$, respectively. Statistical analysis revealed that the differences between the two effects were significant $(\mathrm{P}<0.05)$. These data suggested that in vitro-matured oocytes were inferior to in vivo-matured oocytes in terms of developmental ability and embryo quality. Fertilization by ICSI also had a negative effect on embryo quality.

\section{Discussion}

The low efficiency of in vitro embryo production by ICSI in pigs has
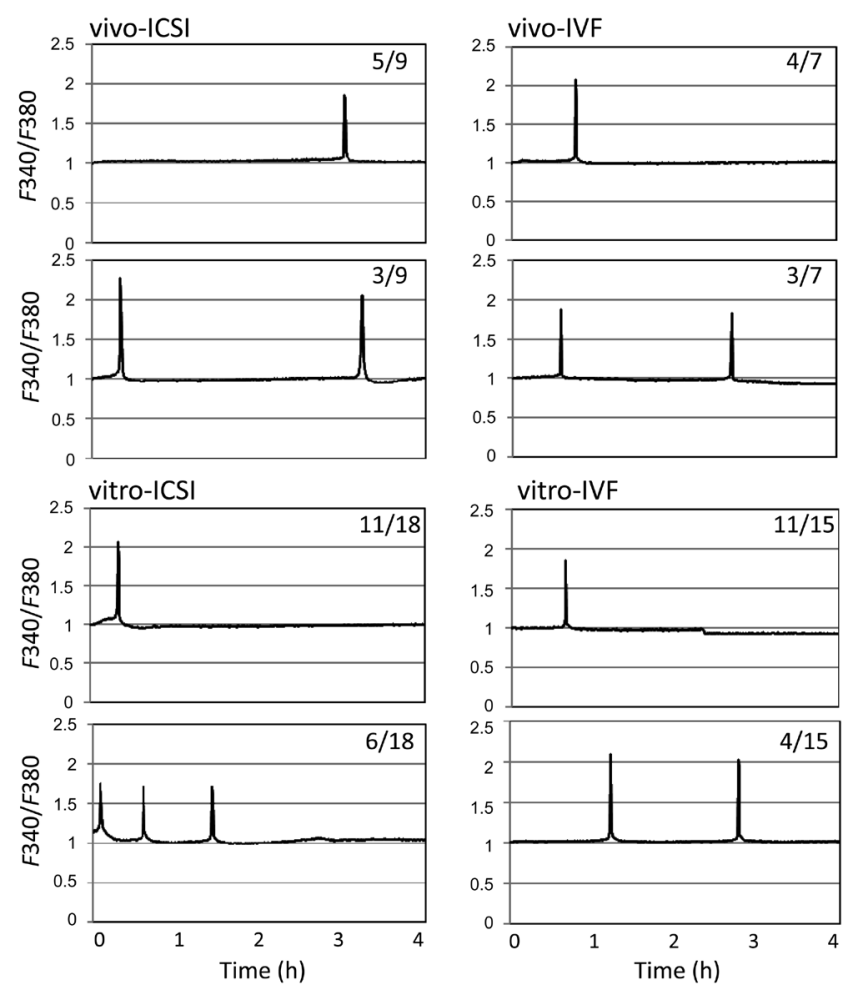

Fig. 2. The typical pattern of intracellular $\mathrm{Ca}^{2+}$ responses in $2 \mathrm{~PB} 2 \mathrm{PN}$ formed pig oocytes, matured in vivo or in vitro after IVF and ICSI. vivo- or vitro-ICSI: in vivo- or in vitro-matured oocytes injected with sperm. vivo- or vitro-IVF: in vivo- or in vitro-matured oocytes inseminated. Data show the ratiometric value of $340 / 380$ $\mathrm{nm}$ fluorescence over time.

been an unresolved problem. We hypothesized that in vitro-matured oocytes or sperm-injected oocytes were unable to generate the pattern of $\mathrm{Ca}^{2+}$ oscillation in "physiological fertilization", and this might 

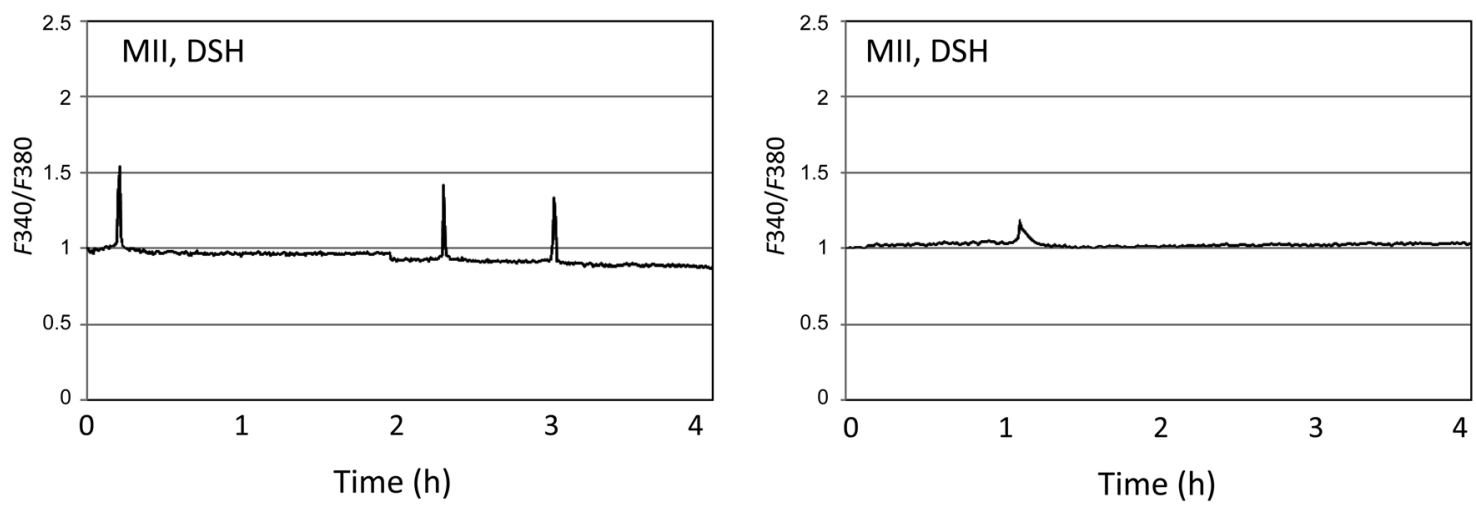

Fig. 3. The pattern of intracellular $\mathrm{Ca}^{2+}$ responses from in vivo-matured oocytes that failed to form PN after ICSI. Both oocytes remained in the MII stage and contained a decondensed sperm head (DSH). Data show the ratiometric value of 340/380 nm fluorescence over time.

Table 3. $\mathrm{Ca}^{2+}$ responses in pig oocytes that failed in PN formation after ICSI

\begin{tabular}{lcccccc}
\hline $\begin{array}{c}\text { Source of } \\
\text { oocytes }\end{array}$ & $\begin{array}{c}\text { No. of oocytes failed } \\
\text { in PN formation }\end{array}$ & $\begin{array}{c}\text { No. of oocytes } \\
\text { with } \mathrm{Ca}^{2+} \text { signal }\end{array}$ & $\begin{array}{c}\mathrm{Ca}^{2+} \text { rise } \\
\text { number }\end{array}$ & No. of oocytes & $\begin{array}{c}\text { Amplitude of } \\
\mathrm{Ca}^{2+} \text { rise * }\end{array}$ & $\begin{array}{c}\mathrm{Ca}^{2+} \text { rise interval } \\
(\mathrm{min}) *\end{array}$ \\
\hline in vivo & 22 & 3 & 1 & 3 & & \\
& & & 2 & 0 & $0.49 \pm 0.16$ & \\
\hline in vitro & 50 & 5 & 1 & 3 & & \\
& & & 2 & 0 & $0.51 \pm 0.06$ & $49.6 \pm 12.06$ \\
\end{tabular}

* Mean \pm SEM for oocytes that exhibited $\mathrm{Ca}^{2+}$ oscillations.

lead to failure of oocyte activation, fertilization, and embryonic development. The pattern of $\mathrm{Ca}^{2+}$ oscillation has been suggested to play an important role in the completion of oocyte activation events, fertilization, and embryonic development $[17,18,31]$. Contrary to our expectations, the pattern of $\mathrm{Ca}^{2+}$ oscillation was not affected by two factors (ICSI and in vitro matured oocyte) because oocytes in the vivo-ICSI and vitro-IVF groups showed a similar pattern of $\mathrm{Ca}^{2+}$ oscillation compared with that of the vivo-IVF group (Fig. 2, Table 2). Some of the in vitro-matured oocytes after ICSI showed a short interval of $\mathrm{Ca}^{2+}$ rise (Table 2). Considering the fact that the pattern was observed in normal fertilized in vitro-matured oocytes after ICSI, the short interval of $\mathrm{Ca}^{2+}$ rise might not have caused the failure of oocyte activation. However, in the present study, whether the short interval of $\mathrm{Ca}^{2+}$ rise shows negative effects on embryonic development is not yet clear.

Half of the in vivo- and in vitro-matured oocytes injected with sperm remained at the M-II stage (Fig. 1) and most of them exhibited no $\mathrm{Ca}^{2+}$ signals (Fig. 3, Table 3). The membranes of pig sperm can be damaged during the freezing and thawing processes associated with cryopreservation [32], and such damage can lead to leakage of intracellular PLC C [29]. Indeed, immediately after thawing, more than half of the pig sperm were found to have lost PLC $\zeta$ immunoreactivity, leading to failure of oocyte activation after ICSI [33]. Use of sperm with appropriate levels of PLC $\zeta$ for ICSI actually increases the efficiency of oocyte activation and normal fertilization [33].
Our findings suggest that the primary reason for failure of oocyte activation after ICSI may be a deficit, rather than a difference, in the pattern of $\mathrm{Ca}^{2+}$ oscillation. Some oocytes that failed to become activated showed small-amplitude $\mathrm{Ca}^{2+}$ oscillation (Fig. 3). Sperm containing an insufficient quantity of PLC $\zeta$ probably induce this kind of small-amplitude $\mathrm{Ca}^{2+}$ oscillation. Even if the level of intracellular $\mathrm{Ca}^{2+}$ increases, $\mathrm{Ca}^{2+}$ signals below a minimum threshold may not be able to induce oocyte activation.

The frequency of $\mathrm{Ca}^{2+}$ oscillation induced by one sperm in a single oocyte is much lower in pig than in hamster (20-30 times/h [34]) and mouse (5-30 times/h [35-37]). Considering that injection of pig sperm into mouse oocytes triggers an extremely high frequency of $\mathrm{Ca}^{2+}$ oscillation [7], the activity of PLC $\zeta$ in pig may be higher than that in mouse. Thus, it appears that the sensitivity of the $\mathrm{IP}_{3} \mathrm{Rs}$ to $\mathrm{IP}_{3}$ or the speed of $\mathrm{Ca}^{2+}$ refilling of ER varies among species.

Use of in vitro-matured oocytes led to a low efficiency of blastocyst formation and a decline in the number of cells per blastocyst (Fig. 4, Table 4). It has been reported that the level of glutathione (GSH) in in vitro-matured oocytes is lower than that in in vivo-matured oocytes [19]. GSH is one of the most important antioxidants, and GSH levels affect oocyte maturation, fertilization, embryonic development, and quality [38-40]. Therefore, increasing the level of GSH in in vitro-matured oocytes may improve the efficiency of embryo production. Moreover, fertilization by ICSI caused no decline in developmental ability (Table 4). Thus, if oocytes show normal 
(a)

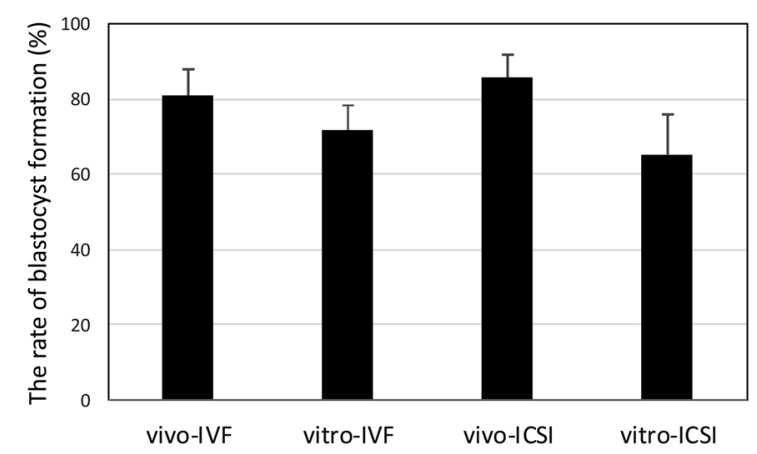

(b)

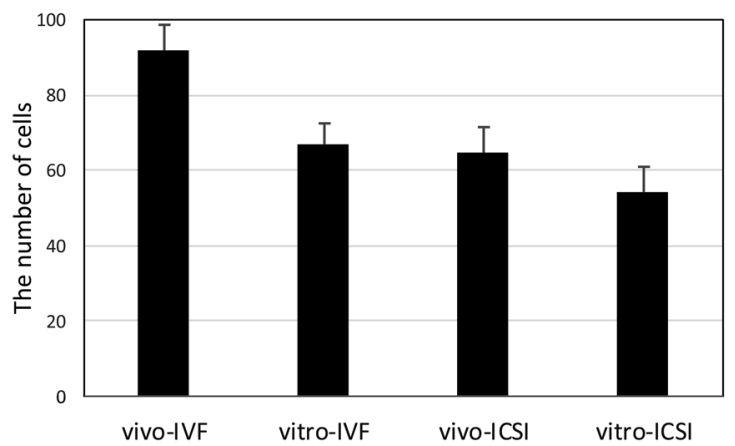

Fig. 4. Effects of the source of oocytes (in vivo- or in vitro-matured) and the fertilization method (IVF or ICSI) on blastocyst formation (a) and number of cells per blastocyst (b). Data are presented as mean \pm SEM for more than three separate experiments.

Table 4. Two-way ANOVA of the rate of blastocyst formation and number of cells per blastocyst

\begin{tabular}{lccc}
\hline \multirow{2}{*}{ Source } & \multirow{2}{*}{ DF $^{\mathrm{a}}$} & \multicolumn{2}{c}{ F-value } \\
\cline { 3 - 4 } & & Blastocyst formation & No. of cells per blastocyst \\
\hline Source of oocyte $^{\mathrm{b}}$ & 1 & $8.62204^{*}$ & $5.616644^{*}$ \\
Fertilization method $^{\mathrm{c}}$ & 1 & 0.73464 & $6.80907^{*}$ \\
\hline
\end{tabular}

${ }^{\mathrm{a}}$ degree of freedom. ${ }^{\mathrm{b}}$ in vivo- or in vitro-matured oocytes. ${ }^{\mathrm{c}}$ IVF or ICSI. $* \mathrm{P}<0.05$.

fertilization after ICSI, they appear to develop better. However, the number of cells per blastocyst after ICSI was lower than that after IVF (Table 4). It has been reported that mouse embryos activated without $\mathrm{Ca}^{2+}$ oscillation have a smaller number of inner mass cells and a higher proportion of apoptotic cells than embryos with $\mathrm{Ca}^{2+}$ oscillation [41]. Therefore, we considered that the small number of cells per blastocyst in ICSI-derived pig embryos might relate to a lack of $\mathrm{Ca}^{2+}$ oscillation. However, in this study, most of the normal fertilized oocytes after ICSI exhibited a pattern of $\mathrm{Ca}^{2+}$ oscillation similar to that after IVF. Thus, the number of cells per blastocyst appears to be influenced by other factors, such as mitochondrial function and expression of genes associated with apoptosis [42, 43]. Further studies will be needed to determine the reason for the small number of cells in ICSI-derived embryos.

In conclusion, in vitro- and in vivo-matured oocytes after ICSI were able to mount a $\mathrm{Ca}^{2+}$ oscillation similar to that of in vivo- and in vitro- matured oocytes after IVF. The main cause of oocyte activation failure in some oocytes after ICSI appeared to be a lack of $\mathrm{Ca}^{2+}$ oscillation, rather than a difference in the pattern of $\mathrm{Ca}^{2+}$ oscillation. Furthermore, normal fertilized oocytes after ICSI showed in vitro developmental ability equivalent to those after IVF.

\section{Acknowledgments}

We would like to thank Ms Iijima K for technical assistance. This study was supported in part by a Grant-in-Aid for Scientific Research (KAKENHI) from the Japan Society for the Promotion of Science (JSPS) to MN (26850172).

\section{References}

1. Miyazaki S, Ito M. Calcium signals for egg activation in mammals. J Pharmacol Sci 2006; 100: 545-552. [Medline] [CrossRef]

2. Saunders CM, Larman MG, Parrington J, Cox LJ, Royse J, Blayney LM, Swann K, Lai FA. PLC $\zeta$ : a sperm-specific trigger of $\mathrm{Ca}\left({ }^{2+}\right)$ oscillations in eggs and embryo development. Development 2002; 129: 3533-3544. [Medline]

3. Ito M, Shikano T, Oda S, Horiguchi T, Tanimoto S, Awaji T, Mitani H, Miyazaki S. Difference in $\mathrm{Ca} 2+$ oscillation-inducing activity and nuclear translocation ability of PLCZ1, an egg-activating sperm factor candidate, between mouse, rat, human, and medaka fish. Biol Reprod 2008; 78: 1081-1090. [Medline] [CrossRef]

4. Cox LJ, Larman MG, Saunders CM, Hashimoto K, Swann K, Lai FA. Sperm phospholipase Czeta from humans and cynomolgus monkeys triggers $\mathrm{Ca}^{2+}$ oscillations, activation and development of mouse oocytes. Reproduction 2002; 124: 611-623. [Medline] [CrossRef]

5. Malcuit C, Knott JG, He C, Wainwright T, Parys JB, Robl JM, Fissore RA. Fertilization and inositol 1,4,5-trisphosphate (IP3)-induced calcium release in type-1 inositol 1,4,5-trisphosphate receptor down-regulated bovine eggs. Biol Reprod 2005; 73: 2-13. [Medline] [CrossRef]

6. Ross PJ, Beyhan Z, Iager AE, Yoon SY, Malcuit C, Schellander K, Fissore RA, Cibelli JB. Parthenogenetic activation of bovine oocytes using bovine and murine phospholipase C zeta. BMC Dev Biol 2008; 8: 16. [Medline] [CrossRef]

7. Kurokawa M, Sato K, Wu H, He C, Malcuit C, Black SJ, Fukami K, Fissore RA. Functional, biochemical, and chromatographic characterization of the complete $\left[\mathrm{Ca}^{2+}\right] \mathrm{i}$ oscillation-inducing activity of porcine sperm. Dev Biol 2005; 285: 376-392. [Medline] [CrossRef]

8. Yoneda A, Kashima M, Yoshida S, Terada K, Nakagawa S, Sakamoto A, Hayakawa K, Suzuki K, Ueda J, Watanabe T. Molecular cloning, testicular postnatal expression, and oocyte-activating potential of porcine phospholipase Czeta. Reproduction 2006; 132: 393-401. [Medline] [CrossRef]

9. Bedford-Guaus SJ, McPartlin LA, Xie J, Westmiller SL, Buffone MG, Roberson MS. Molecular cloning and characterization of phospholipase $\mathrm{C} \zeta$ in equine sperm and testis reveals species-specific differences in expression of catalytically active protein. Biol Reprod 2011; 85: 78-88. [Medline] [CrossRef]

10. Sato K, Wakai T, Seita Y, Takizawa A, Fissore RA, Ito J, Kashiwazaki N. Molecular

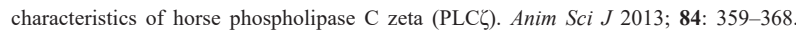
[Medline] [CrossRef] 
11. Coward K, Ponting CP, Zhang N, Young C, Huang CJ, Chou CM, Kashir J, Fissore RA, Parrington J. Identification and functional analysis of an ovarian form of the egg

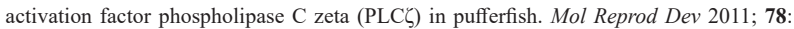
48-56. [Medline] [CrossRef]

12. Coward K, Ponting CP, Chang HY, Hibbitt O, Savolainen P, Jones KT, Parrington J. Phospholipase Czeta, the trigger of egg activation in mammals, is present in a nonmammalian species. Reproduction 2005; 130: 157-163. [Medline] [CrossRef]

13. Mizushima S, Takagi S, Ono T, Atsumi Y, Tsukada A, Saito N, Shimada K. Phospholipase Czeta mRNA expression and its potency during spermatogenesis for activation of quail oocyte as a sperm factor. Mol Reprod Dev 2009; 76: 1200-1207. [Medline] [CrossRef]

14. Miyazaki S, Yuzaki M, Nakada K, Shirakawa H, Nakanishi S, Nakade S, Mikoshiba K. Block of $\mathrm{Ca}^{2+}$ wave and $\mathrm{Ca}^{2+}$ oscillation by antibody to the inositol 1,4,5-trisphosphate receptor in fertilized hamster eggs. Science 1992; 257: 251-255. [Medline] [CrossRef]

15. Tesarik J, Sousa M. Comparison of $\mathrm{Ca} 2+$ responses in human oocytes fertilized by subzonal insemination and by intracytoplasmic sperm injection. Fertil Steril 1994; 62: 1197-1204. [Medline] [CrossRef]

16. Schultz RM, Kopf GS. Molecular basis of mammalian egg activation. Curr Top Dev Biol 1995; 30: 21-62. [Medline] [CrossRef]

17. Ducibella T, Huneau D, Angelichio E, Xu Z, Schultz RM, Kopf GS, Fissore R, Madoux S, Ozil JP. Egg-to-embryo transition is driven by differential responses to $\mathrm{Ca}^{2+}$ oscillation number. Dev Biol 2002; 250: 280-291. [Medline] [CrossRef]

18. Ozil JP, Banrezes B, Tóth S, Pan H, Schultz RM. $\mathrm{Ca}^{2+}$ oscillatory pattern in fertilized mouse eggs affects gene expression and development to term. Dev Biol 2006; 300: 534-544. [Medline] [CrossRef]

19. Brad AM, Bormann CL, Swain JE, Durkin RE, Johnson AE, Clifford AL, Krisher RL. Glutathione and adenosine triphosphate content of in vivo and in vitro matured porcine oocytes. Mol Reprod Dev 2003; 64: 492-498. [Medline] [CrossRef]

20. Mann JS, Lowther KM, Mehlmann LM. Reorganization of the endoplasmic reticulum and development of $\mathrm{Ca}^{2+}$ release mechanisms during meiotic maturation of human oocytes. Biol Reprod 2010; 83: 578-583. [Medline] [CrossRef]

21. Bavister BD, Leibfried ML, Lieberman G. Development of preimplantation embryos of the golden hamster in a defined culture medium. Biol Reprod 1983; 28: 235-247. [Medline] [CrossRef]

22. Kikuchi K, Onishi A, Kashiwazaki N, Iwamoto M, Noguchi J, Kaneko H, Akita T, Nagai T. Successful piglet production after transfer of blastocysts produced by a modified in vitro system. Biol Reprod 2002; 66: 1033-1041. [Medline] [CrossRef]

23. Petters RM, Wells KD. Culture of pig embryos. J Reprod Fertil Suppl 1993; 48: 61-73. [Medline]

24. Kikuchi K, Nagai T, Kashiwazaki N, Ikeda H, Noguchi J, Shimada A, Soloy E, Kaneko H. Cryopreservation and ensuing in vitro fertilization ability of boar spermatozoa from epididymides stored at $4^{\circ} \mathrm{C}$. Theriogenology 1998; 50: 615-623. [Medline] [CrossRef]

25. Ikeda H, Kikuchi K, Noguchi J, Takeda H, Shimada A, Mizokami T, Kaneko H. Effect of preincubation of cryopreserved porcine epididymal sperm. Theriogenology 2002; 57: 1309-1318. [Medline] [CrossRef]

26. Nakai M, Kashiwazaski N, Takizawa A, Hayashi Y, Nakatsukasa E, Fuchimoto D, Noguchi J, Kaneko H, Shino M, Kikuchi K. Viable piglets generated from porcine oocytes matured in vitro and fertilized by intracytoplasmic sperm head injection. Biol Reprod 2003; 68: 1003-1008. [Medline] [CrossRef]

27. Suzuki K, Asano A, Eriksson B, Niwa K, Nagai T, Rodriguez-Martinez H. Capacita- tion status and in vitro fertility of boar spermatozoa: effects of seminal plasma, cumulusoocyte-complexes-conditioned medium and hyaluronan. Int $J$ Androl 2002; 25: 84-93. [Medline] [CrossRef]

28. Somfai T, Ozawa M, Noguchi J, Kaneko H, Karja NWK, Fahrudin M, Nakai M, Maedomari N, Dinnyés A, Nagai T, Kikuchi K. In vitro development of polyspermic porcine oocytes: Relationship between early fragmentation and excessive number of penetrating spermatozoa. Anim Reprod Sci 2008; 107: 131-147. [Medline] [CrossRef]

29. Nakai M, Ito J, Sato K, Noguchi J, Kaneko H, Kashiwazaki N, Kikuchi K. Pretreatment of sperm reduces success of ICSI in the pig. Reproduction 2011; 142: 285-293. [Medline] [CrossRef]

30. Snedecor GW, Cochran WG. 1989 Statistical Methods, edn 8, pp273-296: The Iowa State University Press.

31. Bos-Mikich A, Whittingham DG, Jones KT. Meiotic and mitotic $\mathrm{Ca}^{2+}$ oscillations affect cell composition in resulting blastocysts. Dev Biol 1997; 182: 172-179. [Medline] [CrossRef]

32. Medrano A, Watson PF, Holt WV. Importance of cooling rate and animal variability for boar sperm cryopreservation: insights from the cryomicroscope. Reproduction 2002; 123 . 315-322. [Medline] [CrossRef]

33. Nakai M, Suzuki S, Ito J, Fuchimoto D, Sembon S, Noguchi J, Onishi A, Kashiwazak N, Kikuchi K. Efficient pig ICSI using Percoll-selected spermatozoa; evidence for the essential role of phospholipase C- $\zeta$ in ICSI success. J Reprod Dev 2016; 62: 639-643.

34. Miyazaki S, Hashimoto N, Yoshimoto Y, Kishimoto T, Igusa Y, Hiramoto Y. Temporal and spatial dynamics of the periodic increase in intracellular free calcium at fertilization of golden hamster eggs. Dev Biol 1986; 118: 259-267. [Medline] [CrossRef]

35. Kline JT, Kline D. Regulation of intracellular calcium in the mouse egg: evidence for inositol trisphosphate-induced calcium release, but not calcium-induced calcium release. Biol Reprod 1994; 50: 193-203. [Medline] [CrossRef]

36. Kline D, Kline JT. Repetitive calcium transients and the role of calcium in exocytosis and cell cycle activation in the mouse egg. Dev Biol 1992; 149: 80-89. [Medline] [CrossRef]

37. Nakano Y, Shirakawa H, Mitsuhashi N, Kuwabara Y, Miyazaki S. Spatiotempora dynamics of intracellular calcium in the mouse egg injected with a spermatozoon. Mol Hum Reprod 1997; 3: 1087-1093. [Medline] [CrossRef]

38. de Matos DG, Furnus CC. The importance of having high glutathione (GSH) level after bovine in vitro maturation on embryo development effect of beta-mercaptoethanol, cysteine and cystine. Theriogenology 2000; 53: 761-771. [Medline] [CrossRef]

39. Kishida R, Lee ES, Fukui Y. In vitro maturation of porcine oocytes using a defined medium and developmental capacity after intracytoplasmic sperm injection. Theriogenology 2004; 62: 1663-1676. [Medline] [CrossRef]

40. Jeon Y, Kwak SS, Cheong SA, Seong YH, Hyun SH. Effect of trans-e-viniferin on in vitro porcine oocyte maturation and subsequent developmental competence in preimplantation embryos. J Vet Med Sci 2013; 75: 1277-1286. [Medline] [CrossRef]

41. Rogers NT, Halet G, Piao Y, Carroll J, Ko MSH, Swann K. The absence of a $\mathrm{Ca}(2+)$ signal during mouse egg activation can affect parthenogenetic preimplantation development, gene expression patterns, and blastocyst quality. Reproduction 2006; 132: 45-57. [Medline] [CrossRef]

42. Li XX, Lee DS, Kim KJ, Lee JH, Kim EY, Park JY, Kim MK. Leptin and nonessential amino acids enhance porcine preimplantation embryo development in vitro by intracytoplasmic sperm injection. Theriogenology 2013; 79: 291-298. [Medline] [CrossRef]

43. Schatten H, Sun QY, Prather R. The impact of mitochondrial function/dysfunction on IVF and new treatment possibilities for infertility. Reprod Biol Endocrinol 2014; 12: 111 [Medline] [CrossRef] 